\title{
Synthesis, Structural Characterization, Molecular Docking of Thiophene Derived Schiff base from 4-Amino Indane and Antibacterial, DNA Binding Activities of Its Nickel and Cobalt complexes
}

\author{
K. SUSMITHA ${ }^{1 *}$, MANAN BHARGAVI ${ }^{1}$, D. SUMALATHA ${ }^{2}$ and ALINA JYOTHI JOSEPH ${ }^{3}$ \\ 1,2,3Department of Chemistry, St. Francis College for Women,Street No: 6, Umanagar, \\ Begumpet, Hyderabad, Telangana, 500016, India. \\ ${ }^{*}$ Corresponding author E-mail: susmithakasula@gmail.com \\ http://dx.doi.org/10.13005/ojc/360404
}

(Received: June 05, 2020; Accepted: July 06, 2020)

\begin{abstract}
Novel Schiff base was synthesized from 1:1condensation of thiophene 2-carboxaldehyde and 4-Amino indane. Two solid transition metal complexes ( $\mathrm{Ni}$ and $\mathrm{Co}$ ) were synthesized with this ligand. The structure of ligand (2-THIO-L) and its complexes are confirmed by various spectral characterization methods. 2-THIO-L and its metal complexes are tested for antibacterial activity against Staphylococcus aureus and Escherichia coli. Both show more activity against Gram+ve than Gram-ve bacteria. Molecular docking studies of ligand (2-THIO- L) against MAP2K6 indicated that they are potential inhibitors of carcinogenic receptors. DNA binding interactions of the nickel and cobalt complexes with CT-DNA in tris hydrochloride buffer at $\mathrm{pH}-7.2$ are investigated using UV-Visible spectroscopy. The binding constants are in the range of $10^{5} \mathrm{M}^{-1}$ showed hypochromism which indicate good binding affinity towards CT-DNA.
\end{abstract}

Keywords: 2-THIO-L, 4-AMD, CT-DNA, Metal complexes, DNA binding, MAP2K6, Molecular Docking.

\section{INTRODUCTION}

Schiff bases are the privileged ligands which gained importance due to their stability and flexibility. ${ }^{1}$ They are universal because of their easy synthesis, extensive applications and the ease of different structural modifications. ${ }^{2,3}$ The azomethine group is responsible for various antifungal, herbicidal, antibacterial and analytical activities. ${ }^{4,5}$ Aminoindanes form an important class of novel psychoactive drugs used for psychotherapy. 6,7
They are used for ecstasy and higher dosages lead to serotonin syndrome. Schiff bases containing 4-Aminoindane became significant in medical and pharmaceutical fields due to its wide spectrum of activities like anticancer agents, bronchodilators, anticonvulsants and anti-HIV agents. . $^{8-11}$ Schiff base synthesis and its metal complexes containing 4-aminoindane with Nitro phenol are reported. ${ }^{12,13}$ Our published research paper reported the synthesis of Schiff base containing 4-Aminoindane with 2-hydroxyl benzaldehyde. ${ }^{14}$

This is an Open Access article licensed under a Creative Commons license: Attribution 4.0 International (CC- BY). Published by Oriental Scientific Publishing Company @ 2018 
Mitogen activated protein Kinases belongs to protein kinases that catalyze transfer of phosphate group from ATP to amino acid residues. Non phosphorylated MAP2K6 crystal structure was refined with $3 \mathrm{VN} 9$ in a putative auto inhibition form. Human Non-phosphorylated MAP2K6 crystal structure was binded with an Adenosine Tri phosphate analogue and measured at $2.6 \mathrm{~A}^{\circ}$ resolution. ${ }^{15}$ Mitogen-activated protein Kinase kinase 6 (MAP2K6) belongs to dual specificity protein kinase family. ${ }^{16}$ Receptor tyrosine kinases activate a number signaling pathways upon ligation of receptors in which mitogen activated pathway was one of them. ${ }^{17}$

Apart from this, small organic molecule like Schiff base, complexes with metal cations and interact effectively with macromolecules like DNA, RNA and peptides. As a result DNA binding studies of metal complexes gained significant interest over the past decades. Many compounds by binding to DNA obstruct the multiplication of tumour cells which forms the basis for development of novel anticancer agents. Very little information is existing so far on aminoindanes. Their increasing importance in medicinal research, has motivated us to carry out synthesis of novel Schiff base (2-THIO-L) derived from 1:1 condensation of 4-Amino indane (Structure 1) and thiophene 2-carboxaldehyde (2-THIO) and also to perform Molecular docking. As continuation synthesis, characterization of Co (III) and Ni (II) metal complexes of (2-THIO-L), their antibacterial activity and the binding affinity with calf thymus DNA are also studied.<smiles>Nc1cccc2c1CCC2</smiles>

4- AMD

Structure 1 .

\section{MATERIALS AND METHODS}

\section{Materials}

All chemicals used were of analytical purity. 4-Aminoindane (4-AMD), Thiophene 2-carboxaldehyde (2-THIO), Triethyl amine,
Nickel (II) chloride hexahydrate, Cobalt(II)chloride hexahydrate, Dimethylsulphoxide (DMSO) and Calf thymus DNA were obtained from Aldrich Chemical Company Ltd. Solvents such as ethanol, acetic acid were purified by standard methods. Electronic spectra were recorded with Systronics 2201 Double beam UV-Visible spectrometer ranging 200-1100 nm. Infrared spectra were measured using $\mathrm{KBr}$ pellets on Bruker Fourier Transformation spectrophotometer ranging from 400 to $4000 \mathrm{~cm}^{-1}$. ${ }^{1} \mathrm{H}$ NMR spectra were determined using $\mathrm{CDCl}_{3}$ solvent, at Bruker 400MHZ spectrometer and developed by Mestrec 23 Software. The mass spectra were determined using ESI and LCMS (APCI Probe). The petriplates for antibacterial activity were photographed by using a Smartphone camera (Samsung galaxyM30). For docking studies biological databases like RCSB protein data bank and softwares like Autodock vina, Mercury 3.7 server have been used.

\section{Synthesis of Schiff base}

Dissolve $\left(1.13 \times 10^{-2} \mathrm{moles}\right)$ of 4 -aminoindane in $20 \mathrm{~mL}$ of $99 \%$ pure ethanol and $\left(1.13 \times 10^{-2}\right.$ moles $)$ of thiophene 2-carboxaldehyde solution in $20 \mathrm{~mL}$ of $99 \%$ pure ethanol separately. Mix both the solutions in which a few drops of acetic acid was added and the mixture was refluxed for about 4 hours. On cooling the compound was collected in ice as orange-yellow product which was filtered and recrystallized twice with ethanol. Synthesized Schiff base was obtained as golden yellow crystals, yield $80 \%$, m.p. $148-150^{\circ} \mathrm{C}$. Scheme 1.

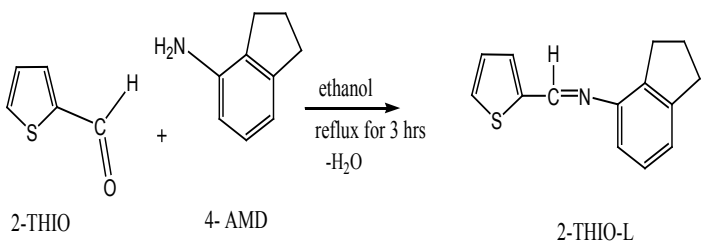

Scheme 1. Preparation of Schiff base ligand with 4-amino indane and thiophene 2-carboxaldehyde

\section{Synthesis of Metal complexes}

The various metal complexes of $\mathrm{Co}$ (III) and $\mathrm{Ni}$ (II) were prepared by refluxing the corresponding $0.3 \mathrm{mmol}$ of the metal (II) chloride solutions with 0.60 $\mathrm{mmol}$ of the Schiff base solution (2-THIO-L), along with $0.06 \mathrm{mmol}$ of triethylamine in $30 \mathrm{~mL}$ ethanol for about 4 hours. This resulted in green colored solution for Nickel complex and violet colored solution for Cobalt complex. The solutions were evaporated and colored precipitates were washed with ethanol and dried over anhydrous $\mathrm{CaCl}_{2}$. Yield $70-75 \%$, m.p. $-150-300^{\circ} \mathrm{C}$. 


\section{Molecular Docking}

Molecular docking helps in studying binding interactions between receptor and ligand. With these interactions one can predict the affinity of binding and activity of ligands to the macromolecular protein receptors.

3VN9 crystal structure of Homo sapiens was downloaded from the RCSB PDB Bank. All the hetero atoms were removed from crystal structure of 3VN9.PDB in order to make receptor free from any ligand molecule before docking.

Extracellular signal regulated kinases, $\mathrm{C}$-jun $\mathrm{N}$ terminal kinases and p38 kinases belong to mammalian MAPK family. These kinases undergo signaling pathway during cell proliferation. MAP2K6 was one of the important p38/MAPK signal pathway. ${ }^{18}$ Under inflammatory and stress conditions MAP2K6 phosporylate and activates p38/MAPK signal pathway (Fig.1). MAP2K6 was associated with various physiological and pathological processes such as cell proliferation, progression, division and inflammatory reactions. MAP2K6 is over expressed in many cancers such as esophageal, stomach and colon. MAP2K6 over expression was not only in these cancers but also in kidney, intestine, and lung cancers indicating its significance in human cancers and act as biomarker to predict or to diagnose the cancers. ${ }^{19}$ As 4-aminoindane derivatives possess anticancer properties, MAP2K6 was selected to carry out docking studies with the synthesized ligand (2- THIO- L)

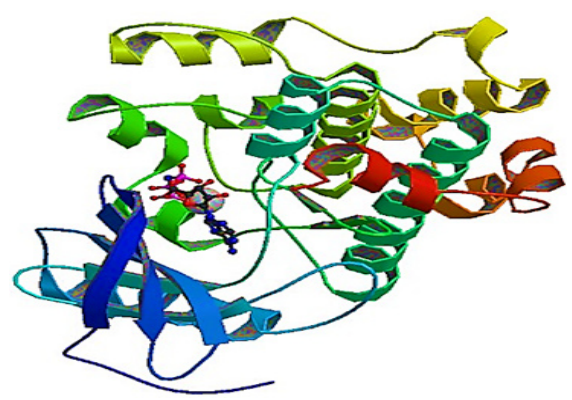

Fig. 1. Refined crystal structure of non-phosphorylated MAP2K6 in a recognized auto inhibition form

Protein preparation

Protein was prepared and saved by adding polar hydrogens, salvation parameters and charges.

\section{Ligand preparation}

The ligand (2-THIO-L) molecule was drawn in chemsketch, which was optimized and saved as
MDL molfile. The saved ligand molecule was opened in Mercury 3.7 server 2 and saved as .mol 2 for docking purpose. In Auto Dock tool ligand preparation has been carried out by detecting roots, choosing torsions and by setting the number of torsions in Torsion Tree and saved in pdbqt format. ${ }^{20-22}$

\section{Grid generation}

Grid box was generated for the macromolecule with prepared ligand by taking active site amino acid residues from PDB sum and assigned $x(-0.442)$, y $(-0.558)$ and $z(0.070)$ co-ordinates from Mercury 3.7 server 2 and saved the molecule as GPF (grid parameter file). After running out auto grid GLG file had been generated this implies the successful generation of grid.

During the docking process DPF file was created and after the process DLG file had been created with which the process was completed. We analyzed the results in DLG file.

\section{Antibacterial activity}

The antibacterial activity of the synthesized ligand (2-THIO-L) and its Nickel, Cobalt complexes were investigated against one Gram (+) i.e. Staphylococcus aureus and one Gram (-) i.e. Escherichia coli bacterial strains using agar diffusion process. The agar medium with concentration $(2 \mathrm{~g} / 100 \mathrm{~mL})$ was autoclaved and then placed in Petri plates for solidification. Three wells $(9 \mathrm{~mm})$ were bored in the agar medium and $0.06 \mu \mathrm{L}$ of ligand solution and metal complexes with concentration of $5 \mathrm{mg} / \mathrm{mL}$ in ethanol were placed in separate labelled wells. Incubation was carried out at $37^{\circ} \mathrm{C}$ for a day and zone of inhibition (in $\mathrm{mm}$ ) was calculated against control for antibacterial assay. ${ }^{23}$

\section{Electronic Absorption Spectra}

Metal ion-DNA interactions can be explored using the experimental method named Ultra Violet absorption spectroscopy. When a metal complex gets inserted into a macromolecule there will be a deviation in its electronic absorption spectrum. The ligand field transition of the metal complex is disturbed when a base binds with it and results in red shift and blue shift, if the binding is intercalative. This is due to the strong stacking interaction between an aromatic chromophore and the base pairs of DNA. The degree of Hypochromism is directly proportional to the percentage of intercalation. ${ }^{24,25}$ 
UV-Absorption titration was carried out using constant concentrations of the complexes with increasing volume $(0-100 \mu \mathrm{l})$ of CT-DNA. While conducting the titration, fixed volume of Calf Thymus DNA was added to complex as well as blank in order to remove interference with CT-DNA. The equation used for calculation of intrinsic binding constant is given as

$[D N A] /\left[\varepsilon_{\mathrm{a}}-\varepsilon_{\mathrm{f}}\right]=[\mathrm{DNA}] /\left[\varepsilon_{\mathrm{b}}-\varepsilon_{\mathrm{f}}\right]+1 / \mathrm{K}_{\mathrm{b}}\left[\varepsilon_{\mathrm{b}}-\varepsilon_{\mathrm{f}}\right]$

The concentration of DNA used is represented as [DNA], $\varepsilon_{\mathrm{a}}, \varepsilon_{\mathrm{f}}$ and $\varepsilon_{\mathrm{b}}$ represents absorption coefficients, which relate to $A_{\text {obs }} . /$ [complex], where $A_{\text {obs }}$. is the extinction coefficient of the free complex and [complex] that of the DNA bound complex. A plot of [DNA]/ $\left[\varepsilon_{a}-\varepsilon_{t}\right]$ against [DNA] provided a slope $1 /\left[\varepsilon_{\mathrm{a}}-\varepsilon_{\mathrm{f}}\right]$ and the intercept was calculated as $\left(1 / \mathrm{K}_{\mathrm{b}}\right)\left[\varepsilon_{\mathrm{b}}-\varepsilon_{\mathrm{t}}\right]$. The ratio of the slope to the intercept gives the value for $\mathrm{K}_{\mathrm{b}}$.

\section{RESULTS AND DISCUSSION}

\section{Physical properties}

The colour, yield and melting point of newly synthesized ligand and its metal complexes are summarised in Table 1.

Table 1: Physical properties of Ligand and its Metal Complexes

\begin{tabular}{lcccc}
\hline Compound & $\begin{array}{c}\text { Empirical } \\
\text { formula }\end{array}$ & Colour & Yield & m.p. \\
\hline Ligand & $\mathrm{C}_{14} \mathrm{H}_{13} \mathrm{NS}$ & Yellow & $80 \%$ & $148-150^{\circ} \mathrm{C}$ \\
Nickel Complex & $\mathrm{C}_{28} \mathrm{H}_{28} \mathrm{~N}_{2} \mathrm{NiOS}_{2} \mathrm{Cl}_{2}$ & Green & $75 \%$ & $150-300^{\circ} \mathrm{C}$ \\
Cobalt Complex & $\mathrm{C}_{28} \mathrm{H}_{26} \mathrm{CoN}_{2} \mathrm{~S}_{2} \mathrm{Cl}_{3}$ & Violet & $73 \%$ & $150-300^{\circ} \mathrm{C}$ \\
\hline
\end{tabular}

Spectral interpretation of 2-THIO-L

The structure of 2-THIO-L was interpreted by UV, Infrared, ${ }^{1} H N M R$ and Mass spectral analysis.

\section{UV- Visible Absorption Spectra}

The UV-Visible absorption spectra of newly synthesized ligand and its Nickel, Cobalt metal complexes were observed in DMSO solvent from 200 to1000 nm (Fig. 2). The UV-spectrum of ligand (2-THIO-L) displayed two absorption peaks at $280 \mathrm{~nm}$ and $360 \mathrm{~nm}$ as a result of $\pi \rightarrow \pi^{*}$ and $\mathrm{n}-\pi^{\star}$ transitions. The UV spectrum of $\mathrm{Ni}$ (II) complex exhibited three bands at $250 \mathrm{~nm}, 340 \mathrm{~nm}$ and 420 $\mathrm{nm}$. The first two absorption bands are because of ligand to metal charge-transfer transitions. The last absorption band is a result of $d-d$ transitions and is given as ${ }^{3} \mathrm{~A}_{2 g}(\mathrm{~F}) \rightarrow{ }^{3} \mathrm{~T}_{1 \mathrm{~g}}(\mathrm{P})$. Co (III) complex showed two absorption bands around $230 \mathrm{~nm}$ and $280 \mathrm{~nm}$ due to ${ }^{5} \mathrm{~T}_{2 \mathrm{~g}} \rightarrow{ }^{5} \mathrm{E}_{\mathrm{g}}$. The above observations suggest an octahedral geometry around Ni (II) and Co (III) ions in their complexes. ${ }^{27}$

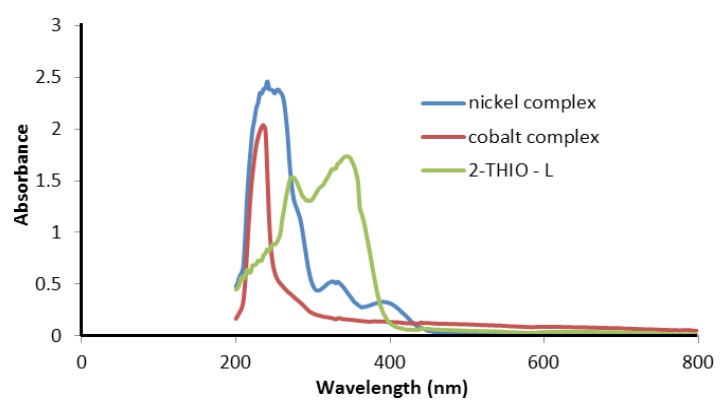

Fig. 2. Electronic spectra of 2-THIO-L and Metal Complexes

\section{Infrared Spectral Interpretation}

Infrared spectra of newly synthesized ligand displayed the following characteristic bands; $\mathrm{sp}^{3} \mathrm{C}-\mathrm{H}$ stretching $\left(3013 \mathrm{~cm}^{-1}\right), \mathrm{C}=\mathrm{CH}$ Aromatic stretching $\left(2945-2970 \mathrm{~cm}^{-1}\right)$, azomethine $\mathrm{HC}=\mathrm{N}$ stretching (1620-1629 $\left.\mathrm{cm}^{-1}\right), \mathrm{C}-\mathrm{C}$ bond stretching in aromatic ring (1593-1560 $\left.\mathrm{cm}^{-1}\right)$ and $\mathrm{C}-\mathrm{N}$ stretching in aromatic amines $\left(1215 \mathrm{~cm}^{-1}\right)$ respectively (Figure 3 ).

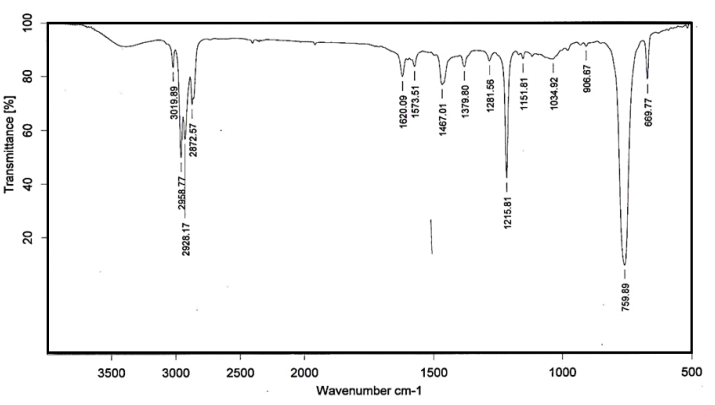

Fig. 3. IR Spectra of the ligand

${ }^{1} \mathrm{H}$ NMR Spectra The ${ }^{1} \mathrm{H}$ NMR of 2- THIO-L in DMSO- $d_{6}$ displayed a peak at $8.6 \delta$ was due to azomethine proton and the aromatic protons resonances in the range of 6.7 to $7.7 \delta$. The aliphatic protons of amino indane ring resonate in the range of 1.5-3.3 $\delta$ (Figure 4).

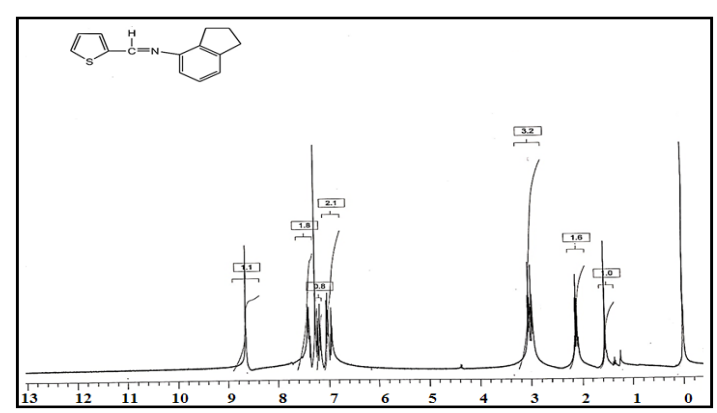

Fig. 4. 'H NMR Spectra of 2-THIO-L 


\section{Mass spectral Interpretation}

The ESI-Mass spectra of 2-THIO-L showed a base peak at $\mathrm{m} / \mathrm{z}=238.18$ whose expected mass was 227.08 (Figure 5).

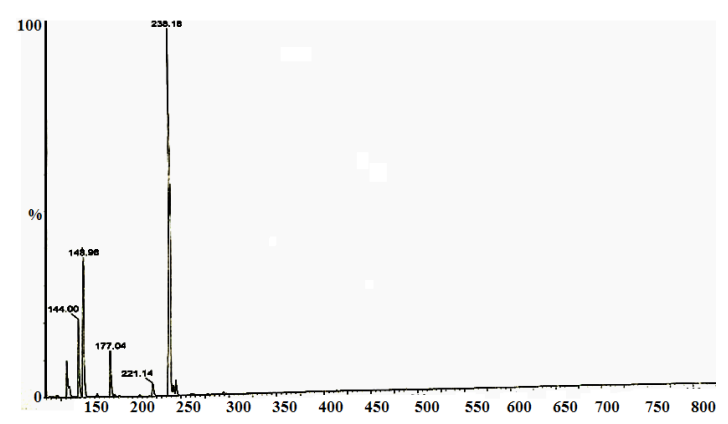

Fig. 5. ESI-Mass Spectra of 2-THIO-L

\section{Molecular Docking Results}

Auto-Dock 1.5.6 docking software was used for Auto grid and Auto dock processes. The docking was used to define the orientation of inhibitors bound in the active site of receptors.

There were 10 conformers generated from each molecule in which best conformer is searched with Lamarckian Genetic Algorithm (LGA). Docking studies of the synthesized ligand was evaluated against MAP2K6 which was responsible for esophageal, stomach and colon cancer.

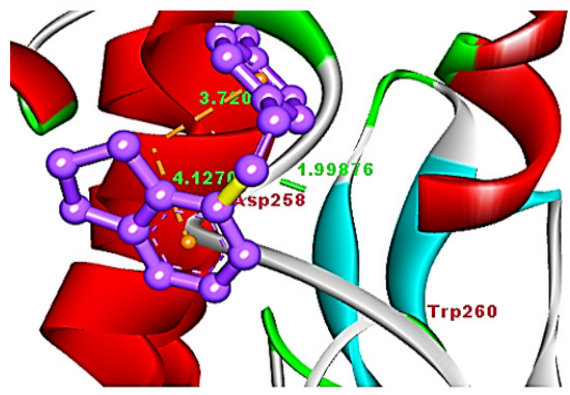

Fig. 6. The binding interactions of 2-THIO-Lwith 3VN9 protein

The 2-THIO-L was showing binding interaction with Asp-258 and Trp-20 (Fig.6). It was also showing negative binding energy value $(-2.87)$ with 3 VN9 protein which suggest that they act as potent inhibitors for the MAP2K6 protein to suppress cancer. From above discussion it was understood that the synthesized ligand possessed important inhibiting property for cancer causing receptors and act as anticanceragents.

\section{Spectral characterization of metal complexes}

The Infrared, proton NMR and LCMS data of the novel complexes were summarized as below.
The Infrared spectra of the complexes and that of 2-THIO-L were matched to decide the binding sites in the complexes. The 2-THIO-L, has an uncoordinated $\mathrm{C}=\mathrm{N}$ stretching band at $1620 \mathrm{~cm}^{-1}$ which is moved to $1616 \mathrm{~cm}^{-1}$ in Cobalt(III), $1499 \mathrm{~cm}^{-1}$ in Nickel (II) complexes. This confirms that azomethine group is involved in bonding to metal ions. Stretching bands due to $(\mathrm{M}-\mathrm{X})$ at $810-550 \mathrm{~cm}^{-1}$ and $(\mathrm{M}-\mathrm{N})$, (M-S) at $500-315 \mathrm{~cm}^{-1}$; in metal complexes was the further proof of coordination (Figure $7 \mathrm{a}, 7 \mathrm{~b}$ ). ${ }^{28}$

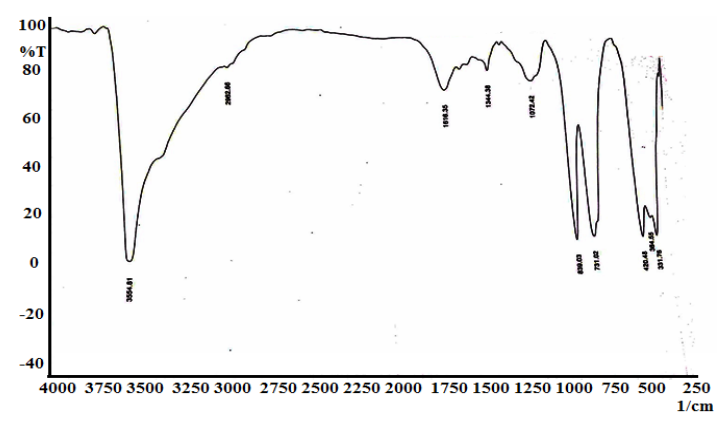

Fig.7a. Infrared spectrum of Cobalt (III) metal complex

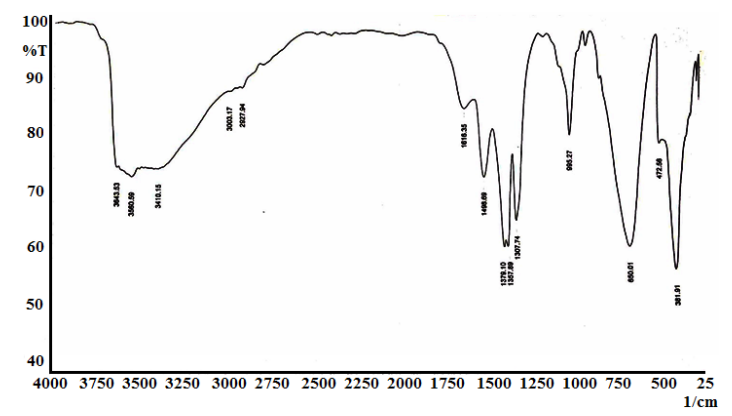

Fig. 7b. Infrared Spectrum of Nickel (II) metal complex

\section{Mass spectra}

The LC-MS data of the complexes of Nickel and cobalt displayed the molecular ion peak at $\mathrm{m} / \mathrm{z}$ $601\left(\mathrm{M}^{+}\right)$and $\mathrm{m} / \mathrm{z} 619\left(\mathrm{M}^{+}\right)$respectively as shown in Fig. 8 a and $8 b .{ }^{29}$

\section{Geometry of the Metal complexes}

From UV, LCMS and IR spectral data the predictable geometry of Nickel and Cobalt metal complexes of 2-THIO- $L$ were found to be octahedral (Figure 9).

\section{Results of antibacterial activity}

The antibacterial results of 2-THIO-L and its metal complexes are found to be active against Staphylococcus aureus (Gram+ve) but did not show any activity against Escherichia coli (Gram-ve) bacterial species (Fig. 10a, 10b). Results confirm that the novel Schiff base and its complexes showed moderate activity. 


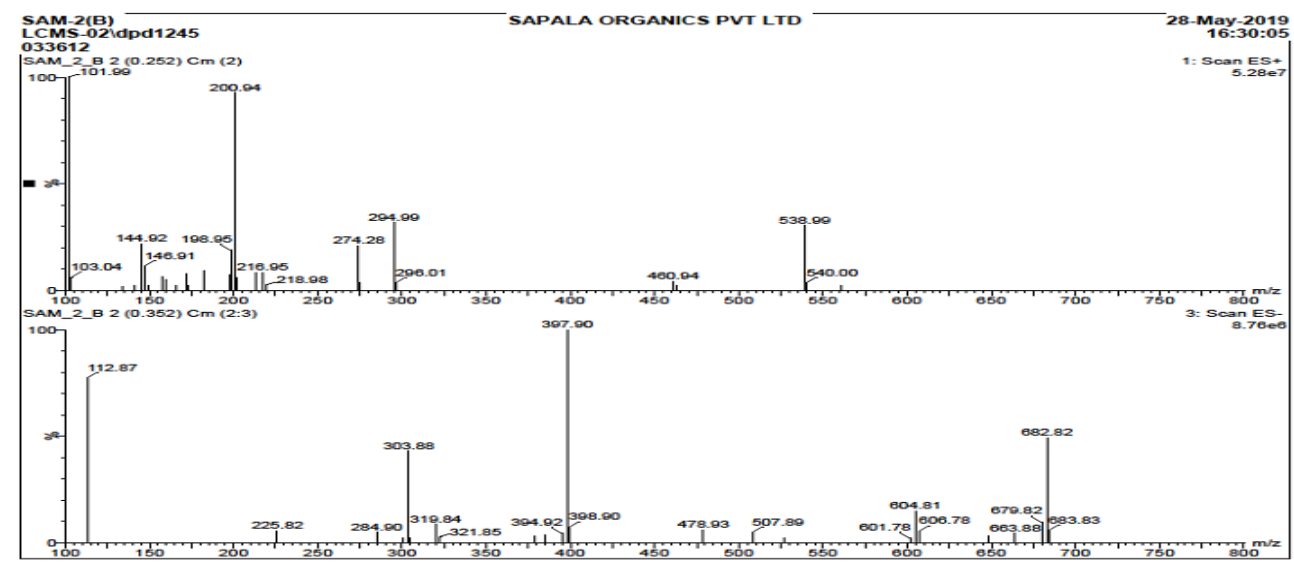

Fig. 8a. Mass spectrum of Nickel (II)-2-THIO-L complex

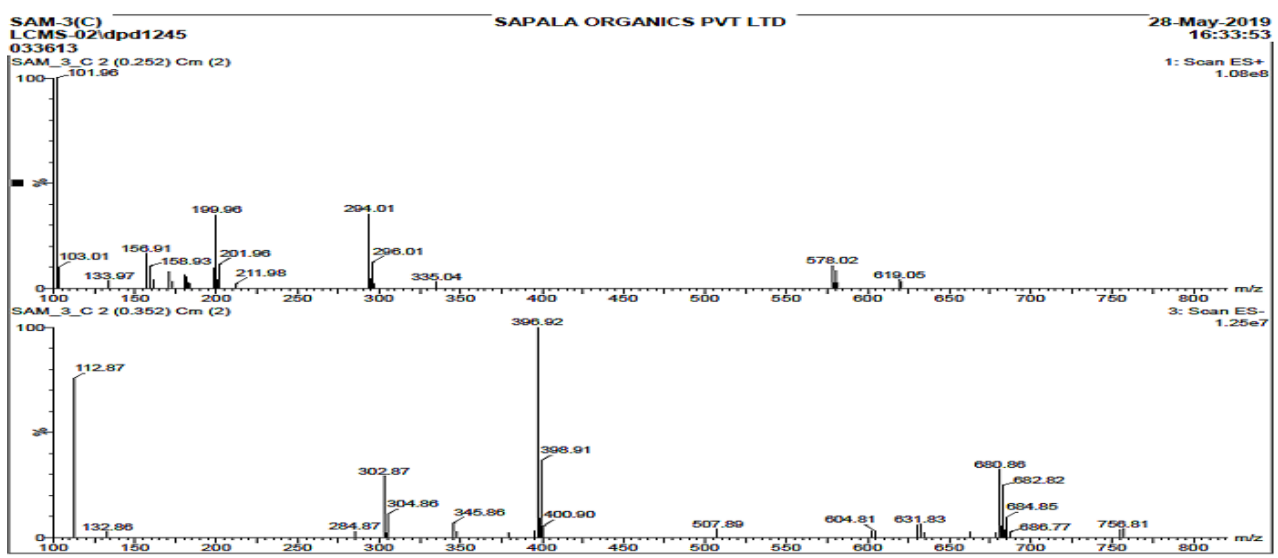

Fig. 8b. Mass spectrum of Cobalt (III)-2-THIO-L complex

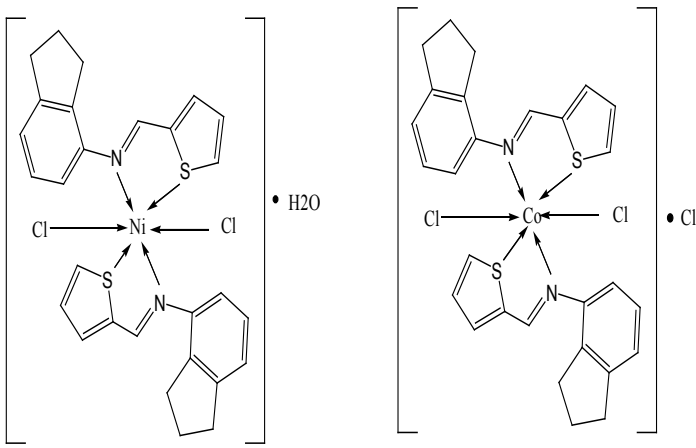

Fig. 9. Proposed structures of complexes of 2-THIO-L
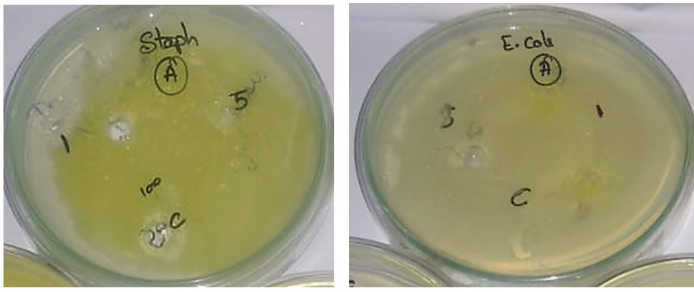

Fig. 10a. Inhibition Zone of 2-THIO-L against S. aureus and E. coli

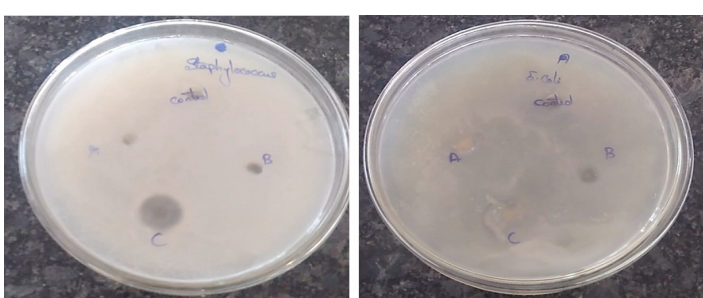

Fig. 10b. Inhibition Zone of metal complexes of 2-THIO-L against S.aureus and E.coli

\section{Results of DNA binding studies}

Metal complexes having planar aromatic groups gets inserted into the grooves of CT-DNA through non covalent interactions which leads to red shift and blue shift. The interaction of the complexes with Calf Thymus-DNA was observed by measuring the changes in the Ultra Violet absorbance of the complexes with the increase in the amount $0-100$ $\mu \mathrm{l}$ of CT-DNA (Fig. 11a, 11b). Adding soluble form of calf thymus DNA to metal complexes in $5 \mathrm{mM}$ Tris $\mathrm{HCl}$ buffer at pH 7.2 showed hypochromism. The calculated $\mathrm{Kb}$ values for metal complexes are 1.22 $\times 10^{5} \mathrm{M}^{-1}$, and $1.66 \times 10^{5} \mathrm{M}^{-1}$ respectively. So, it was 
evident that chromophoric groups of the synthesized metal complexes were involved in intercalative mode of interactions with DNA base pairs.

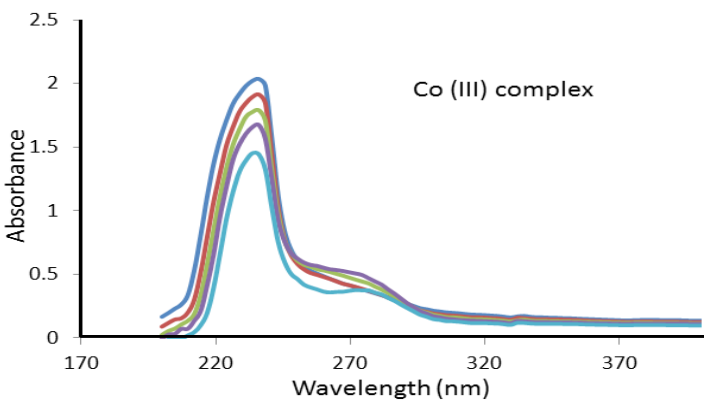

Fig. 11a. Electronic spectra of Co (III) complex in Tris- Hydrochloride buffer at $\mathrm{pH} 7.2$ upon adding 0-100 $\mu \mathrm{l}$ of CT- DNA

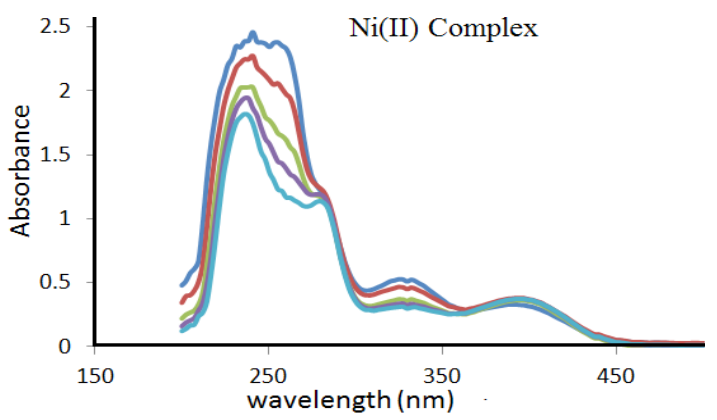

Fig. 11b. Electronic spectra of Ni (II) complex in Tris-Hydrochloride buffer at pH 7.2 upon adding $0-100 \mu \mathrm{I}$ of CT- DNA

\section{CONCLUSION}

The 4-Amino indane derived Schiff base ligand (2-THIO-L) and its nickel, cobalt complexes have been prepared and analyzed spectroscopically. Molecular docking studies revealed that the synthesized ligand was potential inhibitor of cancer causing receptor. The results which we obtained from Auto-Dock were precise and computationally fit for docking of ligand to its specific receptor. From binding constant values $\mathrm{Kb}$, it is observed that interactions between metal complexes and Calf Thymus DNA involves intercalation and results in Hypochromism. Molecular Docking and antibacterial studies reveal that derivatives of 4-Amino indane acts more effectively as anticancer agents.

\section{ACKNOWLEDGEMENT}

Authors are thankful to St. Francis College for Women Departments of Chemistry and Microbiology, for providing lab facilities to carry out the research work. We also express our gratitude to Central Facilities for Research and Development (CFRD), Osmania University, Hyderabad and Sapala Organics Private Limited, Mallapur for the Instrumentation facilities to carry out Spectral characterization.

\section{Conflict of interest}

Authors declare no conflict of interest.

\section{REFERENCES}

1. Djedouani, A.; Bendaas, A.; Boufas, S.; Allain, M.; Bouet, G.; Khan, M. Acta. Cryst., 2007, E63, 1271-1273.

2. Hafeez, Ullah.; Feroza, H.W.; Muhammad, G.; Syed, A.T.; Sadia, A.W. Turk. J Biochem., 2012, 37(4), 386-391.

3. Dhar, D. N.; Taploo, C. L. JSIR., 1982, 41 (8), 501-506.

4. Yang, T. L.; Tai, X. S.; Qin, W. W.; Liu, W. S.; Tan, M. Y. Anal. Sci., 2004, 20, 357-361.

5. Jarrahpour, A. A.; Motamedifar, M.; Pakshir, K.; Hadi, N.; Zarei, M. Molecules., 2004, 9 , 815-824.

6. Nikola, P.; Rachel, R. H.; Tomas, P. Front. Psychiatry., 2017, 8, 236.

7. Linda, D. S.; Anna, R.; York, Schramm.; Marius, C. H.; Matthias, E. L. Biochem. Pharmacol., 2014, 88(2), 237- 244.

8. Stewart, J. M.; Lajos, G.; Whalley, E. T. PCT
Int. Appl., 1996, 1-21.

9. Gademann, K.; Chavez, D. E.; Jacobsen, E. N. Angewandte. Chemie., 2002, 41(16), 3059-3061.

10. KoteswaraRao, N. S. R. R. M. M.; Ram Reddy, M. G. Biometal., 1990, 3, 19-23.

11. Heinzelmann, R. V.; Kolloff, H. G.; Hunter, J. H.; Upjohn, C.; Kalamazoo, M.I. J. Am. Chem. Soc., 1948, 70, 1386-1390.

12. Osowole, A. A.; Daramola, A. O. Elixir Appl. Chem., 2012, 47, 8662-8666.

13. Osowole, A. A.; Ingo Ott.; Oladunni, M. O. Int. J. Inorg. Chem., 2012, 1-6.

14. Arthi, S.; Sumalatha, D.; Susmitha, K.; Bhargavi, M.; Alina Jyothi, J. Asian J. Chem., 2020, 2(3), 539- 542.

15. Takashi, Matsumoto.; Takayoshi, Kinoshita.; Hitomi, Matsuzaka.; Ryoko, Nakai.; Yasuyuki, Kirii.; Koichi, Yokota.; Toshiji, Tada. J. Biochem., 2012, 151(5), 541-549. 
16. Zhanzhan, Li.; Liangfang Shen, Na Li. Cancer. Manag. Res., 2018, 10, 6905-6912.

17. Antonia, L. Pritchard.; Nicholas, K. Hayward. Clin. Cancer. Res., 2013, 19(9), 2301-2309.

18. Eun, K. K.; Choi, E. J. Biochim. Biophys. Acta., 2010, 1802, 396-405.

19. Parray, A. A.; Baba, R. A.; Bhat, H. F. Cancer. Invest., 2014, 32(8), 416-422.

20. Hua Liao, M. M.; Jia-li Kang, PhD.; Wenyan Jiang, M. M.; Cui Deng, M. M.; Jin Yuan, M. M.; Rong Shuai, M. M. Int. J. Gynecol. Cancer., 2015, 25, 1548-1556.

21. Vijesh Arun, A.M.; Isloor, M.; Sandeep Telkar T.; Arunmoli, Hoong-Kun Fun. Arab. J. Chem., 2013, 6, 197 - 204.

22. Bhargavi, M.; Sreekanth, S.; Sarita Rajender, P. Comput. Biol. Chem., 2017, 68, 43-55.
23. Nath, M.; Jairath, R.; Eng, G.; Song, X.; Kumar, A. J. Organomet. Chem., 2005, 690, 134-144.

24. Lokesh, M. R.; Krishnamurthy, G.; Bhojyanaik, H. S.; Shashikumar, N. D.; Murali, P. Krishna.; Sreekanth, B. Der. Pharma. Chemica., 2014, 6(6), 192-202.

25. Pulin, Nath.; Shreedhar, D. D. Der. Pharma. Chemica., 2014, 6(1), 253-261.

26. Saritha, A.; Venkata Ramana Reddy, Ch.; Sireesha, B. J. Chemistry and Chemical Sciences., 2017, 7(2), 138-150.

27. Shakir, M.; Mohammed, A. K.; Nasman, O.S. M. Polyhedron., 1996, 15, 3487-3492.

28. Agarwal, R. K.; Prasad, S. Bioinorg. Chem. Appl., 2005, 3, 271-288.

29. Anupama, B.; Padmaja, M.; Gyana kumari, C. E- J. Chem., 2012, 9(1), 389-400. 